\title{
Application in Psychiatry the Diagnostic Capabilities of Dispersion Mapping of the Alpha Rhythm of the Electroencephalogram
}

\author{
Rosman SV* \\ Physician of functional diagnostics of SBIH, Tver Regional psycho neurological clinic, Russia
}

Submission: October 02, 2017; Published: October 17, 2017

*Corresponding author: Rosman SV, Physician of functional diagnostics of SBIH, Tver Regional psycho neurological clinic, Russia, Email: seros2005@mail.ru

\begin{abstract}
Taking into account modern dimensional approaches to the activity of the brain offers a unique research method is the dispersion of amplitude-frequency characteristics of the alpha rhythm, which is a marker of entropy neuron-glial networks of the brain underlying pathogenesis of mental diseases.
\end{abstract}

Keywords: The variance of the alpha rhythm EEG; A new method of diagnosis of mental illness.

\section{Introduction}

Common place in functional diagnosis of mental illnesses is the claim that electroencephalography (EEG), a non-specific method of research, cannot provide enough conclusive data for the differential diagnosis of mental illness. Mental illness, from F00 to F99 in ICD -10, found no correlation between EEG patterns, despite multiple attempts to attribute some dysrhythmia and phase relationships with individual nosological units.

The working hypothesis of the present study is based on three aspects:

a) In ontogeny, the neural network of the brain is undergoing along with the entire body the process of destruction, the measure of which is the level of entropy.

b) The degree of increase of entropy describes the degree of destruction the neural network, which is reflected in the phenomenon of dispersion of amplitude-frequency characteristics of the alpha rhythm (hereinafter, the dispersion of the alpha rhythm), manifested by splitting of the spectrum of the alpha rhythm, moving it from the material of unimodal to multimodal condition.

c) Verified the measure of dispersion of the alpha rhythm is the dispersion coefficient of alpha-rhythm power ratio of the modal frequency to the total power in the range of 7-13 Hz.

This hypothesis was tested at 2235 patients with different clinical forms of psychopathology [1]. Were studied the amplitude-frequency characteristics of the alpha rhythm EEG by the developed author's method of determining the coefficients of the variance $-C D \alpha 1$ and $C D \alpha 2$. $C D \alpha 1$ is the power ratio of the modal frequency of the alpha rhythm to the total of its capacity throughout the range of the alpha rhythm(7-13 Нz). КДа2 power ratio of alpha rhythm in the range of «frequency modal power $\pm 0.5 \mathrm{~Hz} »$ to total power. Coefficients were calculated using correlation, regression and spectral analysis were compared with the degree of violation of the quantitative EEG in the E. A. Zhirmunskii and clinical picture of the disease. Correlation correlations confirmed the close relationship of the magnitude of these factors with severity of EEG changes and severity of clinical manifestations in the dynamics of treatment of the mentally ill. It was also found that in the norm the average value $\mathrm{CD} \alpha 1$ is not less than 0.25 (25\%), and CD $\alpha 2$ not less than $0.7(70 \%)$.

In this study the measurements were carried out in the two occipital leads. However, this observation, although valuable, could not characterize the brain as a whole. Implementation ideas study the dispersion processes in the brain by EEG over the whole surface scalpel was the creation of a cartogram of the distribution of the variance of the alpha rhythm, both in norm and in various pathologies [2]. Dispersion index of the amplitudefrequency characteristics of the alpha rhythm (further dispersion index) is a method of graphic image, visually showing 
the level CD $\alpha 1$ within any EEG at various frequencies within the range of the alpha rhythm, which is a sequence located in the plane of equiponderate, within which are collected the points with the same values $\mathrm{CD} \alpha 1$ (on the chart they are represented by areas of different colors). It was found that the pattern of dispersion maps very clearly reflects the slightest shifts the split of the power spectrum of the alpha rhythm, the degree of which reflects the level of entropy of a neural network. These method 3450 surveyed patients of various ages with mental illness, the result of which was created the average cartograms for different types of psychopathology it was found that the increase of dispersion of the alpha rhythm is expressed in the distortion of stratification cartograms, «erosion» and expanding the boundaries of low values of $\mathrm{CD} \alpha 1$ with their pronounced shift to the «low-frequency» alpha-rhythm with the transition into the theta range.

The method of dispersion mapping of the alpha rhythm of the EEG reveals very clear objective EEG criteria for the various types of psychopathology. Using this method it is possible to differentiate groups such mental illnesses as schizophrenia (along with schizotypal and delusional disorders), personality disorders, and mental retardation of varying degrees of severity [3]. This technique of EEG diagnostics is innovative and has not been previously applied, neither we, nor abroad (according to the available literature). It is easy to perform and does not require additional material costs - everything is part of a standard EEG study. However, a disadvantage of this method is the relatively high degree of subjectivity in assessing the results of the study.

The starting point for integrating verifiable indices that quantitatively evaluate the mapping changes is the assertion that in the absence of pathological changes in the allocation of capacity in the spectrum of the alpha rhythm, depending on their frequency characteristics, is normal. The deviation from normality of the distribution is a measure of pathological changes. A normal distribution can be represented by two main parameters - kurtosis, and asymmetry. Kurtosis shows how close to the modal value are other values of this distribution, in other words, the normal alpha rhythm is the material of unimodal, and the oscillations are in the narrow frequency range (modal value (Mod) $\pm 0.5 \mathrm{~Hz}$ ). Moreover, if the «classical» normal distribution the characteristic value of about 3 , in the brain, this value is around 6 , indicating the activation of mechanisms that artificially supported monomodality for greater synchronization of activity of cells of a neural network.

The asymmetry shows the shift of the spectrum of alpha rhythm relative to the modal value, high or low frequency region.

Was carried out a mathematical evaluation of these parameters at different mental diseases in 3450 patients.
It was found that the kurtosis, which are called integral index of dispersion of the alpha rhythm (IIDA) consistently reduced with increasing severity of mental illness - from normal to severe dementia. Moreover, the values of their diagnostic groups were statistically significantly different from each other: normal IIDA is 6, 57; personality disorder - 4, 42; when paranoid schizophrenia - 2, 78; in vascular dementia is 2.08. Verified the identified indicators has long been known among clinicians of the phenomenon hypofrontality, which is a cardinal symptom severity of the dementia process. The main index is the integral index of hypofrontality (IIG), which represents IIDA, but defined in the frontal leads. Normal IIG is 5, 17; personality disorder 3,72 ; at paranoid schizophrenia - 1, 40; in vascular dementia $-1,02$. Values of the asymmetry go hand in hand with indexes of dispersion, indicating the increase of slow alpha rhythm, especially in the frontal divisions [4]. Thus, using the methods of dispersion mapping of the alpha rhythm of the routine narrative approaches in psychiatry enriched methods of verificationstatistical medicine, which equips the researcher innovative data and allows solving the following tasks:

a) Early detection of signs of psychopathology in screening studies and in expert prognostic assessment of mental status;

b) Differential diagnosis of psychopathology on the basis of specific dispersion of violations of the alpha rhythm;

c) The ability of prospective study in the dynamics of the course and treatment of mental illness;

d) Update of research on the basis of receipt of verification of the original data; change the amplitude-frequency characteristics of the alpha rhythm by simplifying their statistical processing by methods of mathematical software of the device [5].

\section{References}

1. Maximova NE, Rosman SV, Shpak LV, Zabodaev SV (2016) Possibilities of use of dispersion of an alpha rhythm for screening verification of mental diseases. Mental health 1:16-25.

2. Rosman SV (2013) Diagnostic capabilities of dispersion mapping the alpha rhythm of the electroencephalogram. Mental health 6: 64-69.

3. Rosman SV (2013) Opportunities

4. of the dispersive mapping of the alpha rhythm of electroencephalogram in diagnostics of schizophrenia. Psychiatry 2: 32-37.

5. Rosman SV, Shpak LV (2013) New approaches to the assessment of polymorphism of the alpha rhythm of the electroencephalogram with mental illness. Mental health (2): 39-44.

6. Rosman S (2017) The Theoretical Foundations of Dispersion of Amplitude-Frequency Characteristics of the Alpha Rhythm of the EEG. Glob J Add \& Rehab Med 2(3): 555587. 
This work is licensed under Creative Commons Attribution 4.0 License

DOI: $10.19080 /$ PBSIJ.2017.07.555707

\section{Your next submission with Juniper Publishers} will reach you the below assets

- Quality Editorial service

- Swift Peer Review

- Reprints availability

- E-prints Service

- Manuscript Podcast for convenient understanding

- Global attainment for your research

- Manuscript accessibility in different formats ( Pdf, E-pub, Full Text, Audio)

- Unceasing customer service

Track the below URL for one-step submission https://juniperpublishers.com/online-submission.php 